\title{
Comparative Study of Evaluation of Efficacy and Safety of Combination of Erythromycin and Benzyl Peroxide with Benzyl Peroxide alone in the Treatment of Acne Vulgaris
}

\author{
M YEASMIN ${ }^{\mathrm{a}}$, AZMM ISLAM $^{\mathrm{b}}$
}

Summary:

Objective: Acne vulgaris is the disease of the teenagers as $\mathbf{9 0 \%}$ of them being affected. So many treatment modalities are there - systemic, topical and physical. Among them topical therapy is the main stay of treatment.

Our study was to determine the efficacy and safety of combination of erythromycin/benzyl peroxide compared with benzyl peroxide alone in the treatment of mild to moderate acne.

Method: Patients attended in a Charity Foundation were enrolled for the study after fulfilling the criteria. Among total 50 patients 25 were selected for group $A$ and another 25 for group $B$..

Group A were treated with 3\% erythromycin and 5\% Benzyl peroxide combination and GroupB with 5\% Benzyl peroxide only. Total acne lesions were counted at base line and after

Introduction:

Acne is one of the most common skin disorders in young people specially the teenagers as $90 \%$ of them being affected to some degree in their life span ${ }^{1}$. Acne can give rise to feelings of embarrassment, loss of selfesteem and depression, as well as physical symptoms (such as soreness and pain) $^{2}$. If not treated properly and adequately it may invite many more social and psychological problem due to post acne scar, postinflammatory hyperpigmentation, and disfigurement. Because of the impact and prevalence of acne in the

a. Dr. Monira Yeasmin, Associate Professor, Department of Dermatology and Venereology, Anwer Khan Modern Medical College, Dhaka.

b. Prof. A.Z.M. Maidul Islam, Head of the Department, Department of Dermatology and Venereology, Anwer Khan Modern Medical College, Dhaka.

Address of Correspondence: Dr. Monira Yeasmin , Assistant Professor, Department of Dermatology and Venereology, Anwer Khan Modern Medical College, Dhaka, Bangladesh, Mobile no $(+88)$ 01720205319, E-mail: yeasminm@ymail.com

Received: 25 January 2017

Accepted: 11 July 2017
4,8 and 12 weeks of follow up. Reduction of total no of lesions were seen and analyzed.

Result: At baseline mean of total acne score was $33.60 \pm$ 5.98 and $33.53 \pm 5.68$ in group $A$ and $B(p=0.965)$. After 12 week it was $2.27 \pm 1.08$ and $6.27 \pm 1.57$ respectively in group $A$ and $B(p=0.001)$. Percent reduction of acne severity from base line to final follow up was $93.24 \pm 3.11$ in group $A$ and $81.17 \pm 4.22$ in group $B(p=0.001)$. So we can see better reduction of lesion count in Group A than Group B.

Conclusion: We conclude that Group $A$ is safer and more effective than that of Group B. So the combination of Benzyl peroxide and erythromycin is better than Benzyl peroxide alone.

Key word: Acne, Benzyl peroxide, Erythromycin.

(J Bangladesh Coll Phys Surg 2017; 35: 174-178)

adolescent population, many physicians recommend early and aggressive acne therapy in adolescents ${ }^{3}$.

Several factors contribute to the pathogenesis of acne such as follicular epidermal proliferation, excess sebum production, inflammation and the presence and activity of Propionibacterium acne. Different modalities of treatment are available - systemic, topical and physical. Neither oral therapy (antibiotics and retinoids) nor the topical therapy is being considered as an ideal and fruitful treatment of acne vulgaris.. Systemic oral therapy is not free of poor compliance and side effects unless treated for long duration or due to antibiotic resistance. So ,The topical medication is considered as the main stay of treatment in many patient with mild to moderate acne with exception (nodular and cystic acne). As no single topical agent is completely effective in the treatment of acne vulgaris, combination therapy using agents that have complimentary activity such as a topical retinoid and an antimicrobial agent is a rational treatment approach $^{4-19}$.For inflammatory acne, a topical antibiotic combined with an agent like Benzyl peroxide(BPO) is recommended to increase efficacy and 
prevent the development of Propionibacterium acne resistance ${ }^{5,6}$. As because they target more than one causative factor Combination therapy may provide faster onset of effect and patient who see early improvement may be more likely to adhere to the treatment.

Benzyl peroxide and Erythromycin is one of the combination that has shown significant clinical efficacy in the treatment of acne vulgaris and to be more effective than either agent alone $\mathrm{e}^{7-10}$.

Benzoyl peroxide, is the most widely used topical agents in the treatment of inflammatory acne vulgaris. It is lipophilic and able to penetrate the stratum corneum where it has broad-spectrum antimicrobial activity and mild comedolytic effects ${ }^{11}$ and it does not appear to induce P acnes resistance. ${ }^{12}$ Topical Erythromycin affects the metabolism of Propionibacterium acne ${ }^{13}$. Thereby reducing the level of free fatty acids and has better response on inflammatory lesions than comedones .

So when the both agent combined together exert good response against both inflammatory and noninflammatory acne.

The current study was conducted to evaluate the efficacy and safety of combination therapy that is $3 \%$ Erythromycin and 5\% Benzyl Peroxide in comparison with $5 \%$ Benzyl Peroxide cream alone in the treatment of acne vulgaris.

\section{Materials and Methods:}

This Comparative, single centred open, randomized controlled clinical trial was carried out in private practice centre in Justice Amin Mohammed Foundation Charity OPD between January 2013 to January 2014 . A total no of 50 patients with a minimum 12 inflammatory lesion (papule and pustule ) were selected and they were randomized and divided into two groups (groupA and group-B), each of which include 25 patients.

Patient characteristic were similar in both group (table $1)$. Most of the patients were male.

In case of female who were Pregnant, lactating or with a specific anti-androgenic drug were excluded. Other Exclusion criteria include serious allergy or sensitivity to any drug treatment or Known hypersensitivity to Erythromycin or related compounds ; or history of any major illness.

Complete history, general, physical and dermatological examinations were done for all enrolled patients. For women of reproductive age reproductive history, menstrual history, lactation and pregnancy plan were carefully judged. History and physical findings were recorded in a structured questionnaire. Finally those patients, who matched the inclusion and exclusion criteria according to history, physical examination and freely gave their informed consent, were selected for the study.

Patients of group A were treated with combination of 3\% Erythromycin and 5\% Benzyl Peroxide and group B with 5\% Benzyl Peroxide. Both preparations were administered in once-daily regimen on both sides of the face at bedtime, and the duration of the total treatment period was 12 weeks.

Data were collected in a printed case record form and were analyzed. Finding of the two group were compared. Relative efficacy was assessed by comparison of the reduction from baseline in facial inflammatory lesion counts in the two groups and by comparison of global improvement of (she served not frontal on methods). Relative safety was assessed by comparison of overall tolerance scores at the end of treatment and of local tolerance parameters recorded at each visit .

Result of the present study were compared with those of previous studies.

\section{Result:}

Data was edited, coded and entered into the computer. Data analysis was be performed by Statistical Package for Social Science (SPSS), version-12.. Statistical analyses was done and level of significance was measured by using appropriate procedures like chi square test $\left(\mathrm{C}^{2}\right)$, relative risk (RR) measurement, t-test, and proportion (d) test and others where applicable. Level of significance ( $p$ value) was set at 0.05 and confidence interval at $95 \%$. Results was presented as text and tables

\section{Table-I}

Distribution of age by groups

\begin{tabular}{lccc} 
Age & \multicolumn{2}{c}{ Groups } & p value* \\
\cline { 2 - 3 } in years) & $\begin{array}{c}\text { Group A (BPO }+ \\
\text { Erythromycin) } \\
(\mathrm{n}=25)\end{array}$ & $\begin{array}{c}\text { Group B } \\
(\mathrm{BPO}) \\
(\mathrm{n}=25)\end{array}$ & \\
\hline$<20$ & $18(72.0)^{\#}$ & $18(72.0)$ & \\
$>20$ & $7(28.0)$ & $7(28.0)$ & \\
Total & $25(100.0)$ & $25(100.0)$ & \\
Mean \pm SD & $19.48 \pm 3.28$ & $18.76 \pm 3.09$ & 0.428 \\
\hline
\end{tabular}

$*_{t}$ test was done to measure the level of significance. 
Table-II

\begin{tabular}{lccc} 
& \multicolumn{2}{c}{$\begin{array}{c}\text { Distribution of sex by groups } \\
\text { Sex }\end{array}$} & \multicolumn{2}{c}{ Groups } & p value* \\
& $\begin{array}{c}\text { Group A (BPO + } \\
\text { Erythromycin) } \\
(\mathrm{n}=25)\end{array}$ & $\begin{array}{c}\text { Group B } \\
(\mathrm{BPO}) \\
(\mathrm{n}=25)\end{array}$ & \\
\hline Male & $10(40.0)^{\#}$ & $11(44.0)$ & 0.774 \\
Female & $15(60.0)$ & $14(56.0)$ & \\
Total & $25(100.0)$ & $25(100.0)$ & \\
\hline
\end{tabular}

*Chi-square test was done to measure the level of significance.

\section{Table-III}

\section{Distribution of patient by time of efficacy and by count of lesion}

\begin{tabular}{|c|c|c|c|}
\hline \multirow[t]{2}{*}{ Week } & \multicolumn{2}{|c|}{ Mean lesion counts } & \multirow[t]{2}{*}{ p value* } \\
\hline & $\begin{array}{l}\text { Erythromycin \& } \\
\text { Benzyl peroxide }\end{array}$ & $\begin{array}{c}\text { Benzyl } \\
\text { peroxide only }\end{array}$ & \\
\hline Baseline & $33.56 \pm 5.30$ & $32.56 \pm 3.86$ & 0.450 \\
\hline $4^{\text {th }}$ week & $23.52 \pm 4.48$ & $25.0 \pm 3.27$ & 0.188 \\
\hline $8^{\text {th }}$ week & $12.0 \pm 3.22$ & $16.16 \pm 4.04$ & $<0.001$ \\
\hline $12^{\text {th }}$ week & $1.76 \pm 1.27$ & $5.40 \pm 1.68$ & $<0.001$ \\
\hline $\begin{array}{l}\text { Percent of reduction } \\
\text { from base line to } \\
3^{\text {rd }} \text { follow up }\end{array}$ & on $94.76 \%$ & $83.42 \%$ & $\mathrm{p}=(0.001)$ \\
\hline
\end{tabular}

${ }^{*} t$ test was done to measure the level of significance.

Data was shown as Mean \pm SD.

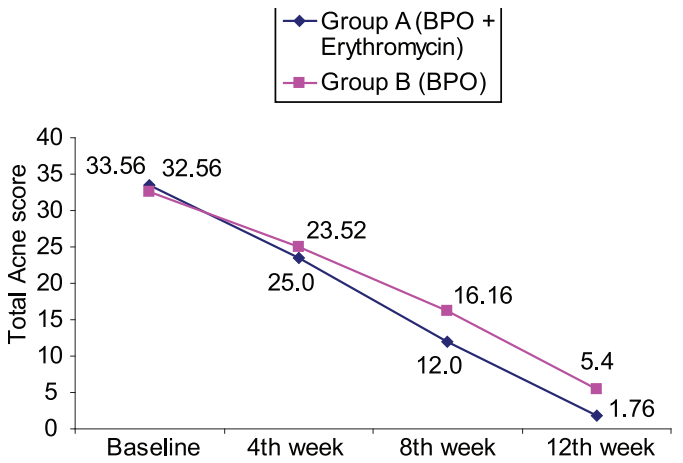

Fig.-I: Line chart of Total Acne score in different follow up.

\section{Table-IV}

Safety score of Erythema, Burning, Scaling, Dryness and Pruritus in 3rd follow up

\begin{tabular}{lccc} 
& \multicolumn{2}{c}{ Groups } & p value* \\
\cline { 2 - 3 } & $\begin{array}{c}\text { Group A (BPO + } \\
\text { Erythromycin) } \\
(\mathrm{n}=25)\end{array}$ & $\begin{array}{c}\text { Group B } \\
(\mathrm{BPO}) \\
(\mathrm{n}=25)\end{array}$ & \\
\hline Erythema & $0.48 \pm 0.51$ & $0.80 \pm 0.50$ & 0.030 \\
Burning & $0.72 \pm 0.61$ & $1.12 \pm 0.53$ & 0.017 \\
Scaling & $0.40 \pm 0.58$ & $1.12 \pm 0.44$ & $<0.001$ \\
Dryness & $0.52 \pm 0.65$ & $0.88 \pm 0.33$ & 0.018 \\
Pruritus & $0.08 \pm 0.28$ & $0.12 \pm 0.33$ & 0.646 \\
\hline
\end{tabular}

$*_{t}$ test was done to measure the level of significance.

\section{Discussion:}

Acne affects $95 \%$ of 16 -year-old boys and $83 \%$ of 16 year-old girls to some degree. The incidence and severity of acne peaks at $40 \%$ in 14-17-year-old girls and at 35\% in boys aged 16-19 years. Despite its spontaneous regression in most patients, acne persists in $10 \%$ of those patients over the age of 25 years $^{14}$. In current study, mean age of Group A patients was $19.48 \pm 3.28$ and Group B was $18.76 \pm 3.09,72.0 \%$ of group A and $72.0 \%$ of Group B was from the age below 20 years and 28.0\% of group A and $28 \%$ of group B was from the age group of 20 to 27 years.

Mean $( \pm \mathrm{SD})$ age of acne onset was $17.63 \pm 3.08$ years and $18.63 \pm 2.08$ years in group A and group B respectively $(\mathrm{p}=0.146)$. Mean duration of disease was $1.60 \pm 0.62$ years and $1.47 \pm 0.57$ years in group $A$ and group $B$ respectively $(\mathrm{p}=0.391)$.

There are believed to be no gender differences in acne prevalence, although such difference are often reported and, very likely, represent social biases ${ }^{1}$. In our study, $40 \%$ of group A and $44 \%$ of group B were male and $60 \%$ and $56 \%$ were female $(\mathrm{p}=0.438)$ in group $\mathrm{A}$ and group B respectively.

Mean score for open comedone, closed comedone, papule and pustule was identical between two groups at base line ( $>0.05)$. Significantly better reduction of acne score for open comedone, closed comedone, papule, pustule and total acne score was noticed at 2 nd and 3rd follow up $(p<0.005)$ in the group A than the group B

Percent reduction of acne severity from base line to final follow up was $94.76 \%$ in group $A$ and $83.42 \%$ in group $\mathrm{B}$ and it was significant between two group $(\mathrm{p}=0.001)$. 
So, in our study of 5\% Benzyl peroxide and 3\% Erythromycin combination achieved better response than the sole application of 5\% Benzyl peroxide.

Safety score for Scaling, Erythema, burning, dryness and pruritus were significantly higher in group B than group A. Events of adverse effects as total safety score was significantly higher in group B than the group A $(\mathrm{p}=0.001)$.

Results and observation of the current study is supporting to different previous studies.

${ }^{15}$ Chaker DK et al conducted a double-blind, comparative randomized study where 165 patients were treated with (1) a combination of 3\% erythromycin and 5\% benzoyl peroxide in a gel, (2) $5 \%$ benzoyl peroxide gel, (3) $3 \%$ erythromycin gel, and (4) the gel vehicle in a once daily regimen for 10 weeks. Responses, irritation as well as possible other adverse effects were recorded after 4,8 and 12 weeks of treatment and the improvement, compared to baseline, assessed in all included patients. Parameters of efficacy were - the various acne lesions count, the overall acne severity grade and the calculated total of acne lesions number count.

In that clinical trial they found that combination of product of erythromycin and benzyl peroxide was more effective than benzyl peroxide alone and the most dramatic effect was on combined inflammatory lesions, i.e., papules and pustules ${ }^{2}$

They concluded that the combination of Benzoyl peroxide gel and the Erythromycin gel were superior to the control gel and to the Benzyl peroxide alone. So the combination product was more effective and superior than any of the others. Our study was very similar to this study regarding study design, methodology and the findings. In our study we also find the same result.

The rationale for the combination has been examined in several other clinical studies.

${ }^{16} \mathrm{Gupta} \mathrm{AK}$ et al in an another comparative study found, $3 \%$ erythromycin $/ 5 \%$ benzoyl peroxide was superior in reducing the number of inflammatory lesion and non inflammatory lesions and provide a greater beneficial effect than $0.025 \%$ tretinoin /erythromycin $4 \%$.

${ }^{17} \mathrm{Chu}$ A et al observed that combination of of Benzyl peroxide and the Erythromycin gel was superior to its individual component. And advantage of this combination may cause reduction in drug resistance $p$. acne.
Burke $\mathrm{B}^{18}$ et al in a double-blind clinical study of ninety-four subjects used $1.5 \%(\mathrm{w} / \mathrm{v})$ erythromycin lotion \& 5\% (w/v) benzoyl peroxide gel and found both the trearment were effective in reducing the number of small inflamed lesions significantly and the over-all acne severity. However, benzoyl peroxide also significantly reduced the number of non-inflamed lesions whereas erythromycin has the value in the treatment of mild or moderate acne vulgaris.

${ }^{2}$ Ozolins M, Eady EA, Avery AJ, et al in 2004 conducted a large trial on 649 patient aged $13-39$ yrs to compare five treatment group . oral oxytetracycline $500 \mathrm{mg}$ b.d group , oral minocycline $100 \mathrm{mg}$ once daily group , topical Benzamycin (3\% erythromycin $+5 \%$ benzoyl peroxide) b.d. group topical $2 \%$ erythromycin o.d. and topical 5\% benzoyl peroxide o.d group and topical $5 \%$ benzoyl peroxide b.d. group.

The best response rates were seen with two of the topical regimens erythromycin plus benzoyl peroxide administered separately or in a combined proprietary formulation, compared with benzoyl peroxide alone, oxytetracycline and minocycline although differences were small. They concluded that Benzoyl peroxide was associated with Greate $r$ frequency and severity of local irritant reactions. The same finding we find in our study with group B and it is suggested that the use of a combination of topical benzoyl peroxide and erythromycin gives less irritation and better quality of life. The same result we got in our study. So it proves that Benzyl peroxide and Erythromycin combination is safer and effective treatment. So The Combination therapy for the topical treatment of acne vulgaris using benzoyl peroxide (BPO) and an antibiotic is more efficacious and better tolerated than treatment with either component alone Moreover, the addition of BPO to antibiotic therapy is recommended as a means of preventing the development of Propionibacterium acnes antibiotic resistance.

\section{Conclution:}

The result of this current study concluded that Combination of benzyl peroxide and topical antibiotic is a rational approach in the treatment of Acne vulgaris, Combination therapy showed effective and safe .so Combination of benzoyl peroxide and erythromycin Can be effectively used in the treatment of Acne vulgaris. 


\section{Reference:}

1. Kubba R, Bajaj AK, Thappa DM, Sharma R, Vedamurthy M, Dhar S. Acne in India: Guidelines for management - IAA Consensus Document: Epidemiology of acne. Indian J Dermatol Venereol Leprol 2009;75(Suppl 1):S3

2. Ozolins M, Eady EA, Avery AJ, et al. Comparison of five antimicrobial regimens for treatment of mild to moderate inflammatory facial acne vulgaris in the community: randomised controlled trial. Lancet. 2004;364(9452): 2188-95.

3. Odom RB, James WD, Berger TG, (editors) 2000, Andrews' Diseases of the Skin. Clinical Dermatology, $9^{\text {th }}$ ed. W. B. Saunders Company, Philadelphia;. pp. 284-306

4. Leyden J.Are 2 combined antimicrobial mechanisms better than 1 for the treatment of acne vulgaris ? clinical and antimicrobial result of a topical combination product containing $1 \%$ clindamycin and $5 \%$ benzyl peroxide introduction.Cutis .2001;67(2 suppl):5-7.

5. Leyden JJ, Shalita AR.- Rational therapy for acne vulgaris: an update on topical treatment. J Am Acad Dermatol, 1986, $15,907-914$.

6. Leyden JJ, McGinley KJ, Cavalieri S, et al.Propionibacterium acnes resistance to antibiotics in acne patients. J Am Acad Dermatol, 1983, 8, 41-45.

7. Eady EA, Farmery MR, Ross JI, Cove JH, Cunliffe WJ. Effects of benzoyl peroxide and erythromycin alone and in combination against antibiotic sensitive and resistant skin bacteria from acne patients. Br J Dermatol 1994;131:331-6.

8. Mills OH, Berger RS.- Comparison of the combination of erythromycin/ benzoyl peroxide topical gel to clindamycin phosphate solution in the treatment of acne vulgaris. Cutis 1992, 49, 5-7.

9. Leyden JJ.- Open -label evaluation of topical antimicrobial and anti-acne preparations for effectiveness versus Propionibacterium acnes in vivo. Cutis 1992, 49, 8-11.

10. Shalita AR, Chalker DK, Ellis CN, et al.- A multicenter, double blind, controlled study of the combination of erythromycin/ benzoyl peroxide, erythromycin alone, and benzoyl peroxide alone in the treatment of acne vulgaris. Cutis, 1992, 49, 1-4.

11. Tailor GA, Shalita AR. Benzoyl peroxide based combination therapies for acne vulgaris: a comparative review. American Journal clin Dermatol 2004;5:261-265.

12. Thiboutot D, Gollnick H, Bettoli V, et al. New insights into the management of acne: an update from the Global Alliance to Improve Outcomes in Acne group. J Am Acad Dermatol. 2009;60(5 Suppl):S1-50.

13. Fulton JE, Pablo G.Topical antibacterial therapy in acne .Study of the family of erythromycin.Arch Dermatol1974;110 83-6.

14. Ebling FJG, Cunliffe WJ. Disorders of the sebaceous glands. In:Textbook of Dermatology (Champion RH, Burton JL, Burns DA,Breathnach SM, eds), 6th edn, Vol. 3. Oxford: Blackwell Science, 1998; 1942.

15. Chalker DK, Shalita A, Smith JG, Swann RW. A double-blind study of the effectiveness of a $3 \%$ erythromycin and $5 \%$ benzoyl peroxide combination in the treatment of acne vulgaris. Journal of the American Academy of Dermatology 1983;9: 933-936,

16. Gupta $\mathrm{AK}^{1}$, Lynde CW, Kunynetz RA, Amin S, Choi K, Goldstein E A randomized, double-blind, multicenter, parallel group study to compare relative efficacies of the topical gels $3 \%$ erythromycin $/ 5 \%$ benzoyl peroxide and $0.025 \%$ tretinoin/ erythromycin $4 \%$ in the treatment of moderate acne vulgaris of the face. J Cutan Med Surg. 2003;7(1):31-7.

17. Chu A, Hurber FJ ,Plott RT. The comparative efficacy of ), Benzyl peroxide $5 \%$ and Erythromycin $3 \%$ gel and Erythromycin $4 \%$ /zinc $1.2 \%$ in the treatment of acne vulgaris.Br.J Dermatol 1997 ;136:235-238.

18. BURKE, B., EADY, E.A. and CUNLIFFE, W.J. (1983), Benzoy 1 peroxide versus topical erythromycin in the treatment of acne vulgaris. British Journal of Dermatology, 108: 199-204.

19. Weiss JS .Current options for the topical treatment of acne vulgaris.Paediatrics Dermatol.1997;14;480-488. 